\title{
Representantes e dominantes: Os governantes e as relações de classe em Portugal
}

Representatives and Dominants: Rulers and Class Relations in Portugal

Représentants et dominants: Les gouvernants et les rapports de classe au

Portugal

Adriano Campos, Jorge Costa, João Teixeira Lopes, Francisco Louçã e Nuno Moniz

\section{OpenEdition}

\section{Journals}

\section{Edição electrónica}

URL: http://journals.openedition.org/rccs/6095

DOI: $10.4000 /$ rccs.6095

ISSN: 2182-7435

Editora

Centro de Estudos Sociais da Universidade de Coimbra

Edição impressa

Data de publição: 1 dezembro 2015

Paginação: 55-74

ISSN: 0254-1106

\section{Refêrencia eletrónica}

Adriano Campos, Jorge Costa, João Teixeira Lopes, Francisco Louçã e Nuno Moniz, « Representantes e dominantes: Os governantes e as relações de classe em Portugal », Revista Crítica de Ciências Sociais [Online], 108 | 2015, posto online no dia 16 dezembro 2015, consultado o 14 novembro 2019. URL :

http://journals.openedition.org/rccs/6095; DOI : 10.4000/rccs.6095 


\section{ADRIANO CAMPOS, JORGE COSTA, JOÃO TEIXEIRA LOPES, FRANCISCO LOUÇÃ, NUNO MONIZ}

\section{Representantes e dominantes: Os governantes e as relações de classe em Portugal}

Este artigo trata das ligações estabelecidas entre os detentores de capital e os grupos de governantes e ex-governantes, a partir de uma perspetiva crítica capaz de realçar o papel do Estado na estruturação do poder económico. É dado especial enfoque ao processo de cooptação, numa análise que engloba os dados referentes aos 776 governantes que ocuparam 1281 cargos nos 19 governos constitucionais (1976-2014).

Palavras-chave: burguesia; classes sociais; cooptação social; Estado; poder económico.

\section{Introdução}

Precisar as pertenças e as relações de classe, nas suas agregações coletivas e manifestações individuais, estabelecidas pelos titulares do poder executivo em Portugal no período da democracia constitucional é a carência sociológica existente que nos propomos a tratar neste artigo. Esse esforço analítico implica delimitar um aporte teórico e conceptual capaz de dotar de sentido e classificação o diminuto universo constituído pelos 776 ministros e secretários de Estado, que integraram os 19 governos constitucionais (1976-2013). Para tal, procura-se expandir, sob um prisma particular, a análise realizada recentemente sobre a realidade da burguesia portuguesa e para a qual remetemos nas questões de maior abrangência (Louçã, Lopes e Costa, 2014).

Este estudo do universo constituído pelos indivíduos que desempenharam funções de governação, daqui em diante designados por governantes, seguiu uma análise longitudinal dos percursos individuais, estabelecendo como indicadores relevantes: o capital escolar; o percurso profissional; a ocupação de cargos públicos; as relações no domínio da propriedade. $\mathrm{O}$ resultado deste exame, ${ }^{1}$ inédito na sociologia portuguesa, procura contribuir para a agregação

1 Toda a informação desta base de dados está disponível em: http://www.osburgueses.net/consulta/ index.html. 
de conhecimento das relações de classe em Portugal e confrontar duas questões sociológicas específicas, sumariadas nesta introdução: (i) situar em que extensão a passagem por cargos executivos de governação resulta num processo de mobilidade social ascendente por parte dos atores envolvidos; (ii) aferir de que forma o processo de cooptação política para os altos cargos do Estado se relaciona com os interesses dos detentores de capital numa dada estratégia de acumulação.

\section{Da burguesia ao Estado}

Em Os burgueses (Louçã, Lopes e Costa, 2014), defendemos que a burguesia se define pela relação social de acumulação de valor numa sociedade de classes, por via da exploração direta e indireta, mas também pela sua capacidade de cooptação, reprodução, governação e legitimação nas relações estabelecidas com as outras classes. A burguesia é, portanto, a classe que detém os meios de produção e que determina a reprodução da estrutura social da sociedade moderna. É a classe mais visível, homogénea e consciente, mas também a mais desconhecida. Caracterizar este processo combinado de dominação implica, antes de mais, situar as relações específicas através das quais se operam os padrões de domínio da burguesia, nomeadamente as que se estabelecem para lá do mero plano económico.

Nessa abordagem, a existência e a reprodução do Estado como arena de confronto constitui um campo suplementar e não secundário das relações de classe, uma vez que reflete, mesmo que de forma distorcida, o conflito social que engendrou a sua própria construção e lhe concedeu uma função de poder na reprodução da estrutura social. O foco não reside apenas nas instituições que asseguram funções específicas e nessa sua pluralidade constituem os diversos ramos do Estado - governo, administração central, aparelho coercivo, poder judicial - mas antes na conexão entre a função dessas instituições e as formações sociais e históricas que as erigiram, revelando as bases sobre as quais é produzida a sua legitimidade.

O debate em torno do binómio Estado-sociedade remonta aos clássicos da sociologia, estabelecendo correntes dissonantes no que respeita à leitura das ligações estabelecidas entre as esferas económica e política. Sumariamente, podemos identificar uma primeira abordagem que dá primazia à coesão social ${ }^{2}$

\footnotetext{
${ }^{2} \mathrm{O}$ conceito de coesão é aqui utilizado a partir da relação estabelecida entre os indivíduos e o Estado, assim como entre si próprios. As teorias aqui apresentadas, de uma forma geral mas não homogénea, defendem que "a coesão e a harmonia sociais exigem da parte dos indivíduos uma relativa conformidade com as normas e os valores vigentes na sociedade, doutro modo sujeitam-se a sanções negativas. Ou seja, os que cumprem e correspondem serão, em consonância com a ideologia meritocrática, recompensados em rendimento, prestígio e poder e os que eventualmente transgridam e não partilhem as regras estabelecidas pela organização social serão considerados casos desviantes e, como tal, deverão ser negativamente sancionados” (Silva, 2009: 45).
} 
entre os grupos e classes sociais, presente em várias escolas de pensamento, podendo ser encontrada de forma vincada na teoria social dos (estruturo)funcionalistas - de Durkheim (1973) até Parsons ${ }^{3}$ (1988) - assim como em parte da teoria económica (neo)liberal - de Adam Smith a Friedman (1962). Enquanto os primeiros tendem a valorizar a função integradora do Estado perante sociedades em processo de rápida transformação, a matriz liberal valoriza a separação existente entre a esfera económica e a esfera política. Nesta visão, o Estado surge como uma entidade acima dos conflitos endógenos da sociedade, garantindo o exercício do poder sem intromissão de maior nas relações de propriedade, que se apresentam, por sua vez, naturalizadas e desligadas da relação de forças existente no plano político.

Neste artigo seguiremos uma abordagem teórica distinta. A análise acumulada pelas correntes críticas - do contributo marxista aos (neo)weberianos, ${ }^{4}$ não obliterando os teóricos do poder e das elites, como Wright Mills (1981) que desvendaram dimensões do conflito social na base histórica e substantiva da formação dos Estados fornece-nos claras evidências das ligações intrínsecas estabelecidas entre o poder económico e o poder político. Seguindo o enfoque proposto por Bob Jessop (1990), assumimos que a particularidade do Estado, caracterizada pela dissociação formal da estratégia de acumulação de valor dominante em cada época, está intimamente relacionada com as suas formas de representação. Por outras palavras, à conhecida súmula de Max Weber, do "Estado como monopólio do uso legítimo da violência física num dado território" (2004: 525), é necessário acrescentar o Estado como produtor de representações legitimadas, permitindo aos seus dirigentes a reivindicação de uma autonomia, mais ou menos relativa, em face dos interesses divergentes presentes na sociedade.

Ainda segundo Jessop, o facto de o poder de Estado no capitalismo tardio se estabelecer em função da organização social de uma classe particular, a burguesia, não anula a existência de "projetos hegemónicos diferentes".

\footnotetext{
${ }^{3}$ Este autor apresenta uma análise da ordem social que assenta na diferença "funcional" entre os indivíduos, ou seja, uma diferença "saudável" ao nível das posições sociais, onde os mais capazes ocupam as melhores posições, advogando assim uma causalidade direta entre a integração/ submissão social e a aceitação total e consensual da autoridade civil através da qual a ordem é estabelecida. ${ }^{4}$ Para uma leitura dos contributos (neo)weberianos da análise das classes sociais e do Estado, cf. Silva (2009: 61).

5 Jessop (1990: 154) caracteriza um projeto hegemónico a partir de três fatores: (i) a sua "determinação estrutural", que motiva o privilégio atribuído a algumas partes em detrimento de outras, o que pode ser conceptualizado como a "seletividade estrutural" do Estado, resultando em favor de uma classe (ou fração de classe); (ii) a sua "orientação estratégica", que condiciona a integração de várias forças como sujeitos de um interesse específico sob um escopo "nacional e popular", intermediando os diversos dissensos sem pôr em causa o projeto geral; (iii) a sua "relação com o regime de acumulação", que varia historicamente na forma como garante a produtividade da economia e a despossessão das classes subordinadas.
} 
As vias pelas quais os aspetos substantivos do Estado encontram o respaldo ou a rejeição de uma base social muito heterogénea são variáveis. A viabilidade de cada projeto hegemónico, que tenha no Estado o seu principal pilar de sustentação e responda à lógica de acumulação de valor, está dependente de múltiplos fatores, entre os quais a capacidade de conciliar interesses particulares divergentes entre a própria classe economicamente dominante, de forma a não prejudicar a reprodução do valor em geral. ${ }^{6}$ Desse modo, do fecundo debate sobre a função e a autonomia do Estado numa sociedade de classes, ${ }^{7}$ estabelecemos que os meios de representação política, assim como as características e os arquétipos do seu exercício, constituem um objeto de suma importância na apreensão do problema: o que importa aqui compreender é como as formas de cooptação política para os altos cargos do Estado e o papel desempenhado pelos ex-governantes se relacionam com os interesses dos detentores de capital numa dada estratégia de acumulação.

A existência de diversos "formatos de representação", que condicionam a seleção dos representantes políticos, não determina por si só os meios pelos quais essa representação é assegurada, mas antes remete para o contexto no qual a classe economicamente dominante garante a reprodução das suas posições por via do Estado (Therborn, 1978: 183). A arqueologia de um debate particular ajuda-nos a avançar. Perfilando a abordagem estruturalista, Poulantzas (1978: 147) recusa a conceção instrumentalista do Estado concebido como utensílio passivo, manipulado por uma só classe ou fração de classe, realçando o facto de o "pessoal do Estado" constituir uma categoria social por efeito da própria organização estatal, mas uma categoria que não é, contudo, desprovida de um lugar de classe: "As contradições e divisões no seio do bloco no poder repercutem-se, pois, no seio das altas esferas do Pessoal do Estado. Mais: em virtude da pertença de classe pequeno-burguesa de largas partes deste pessoal, as lutas populares afetam-no forçosamente". Daí que mesmo avançando a conceptualização de uma "fração hegemónica", que assegura a aliança coerente das classes dominantes, Poulantzas não estabeleça uma relação desse domínio como sendo dependente da ocupação dos altos cargos do Estado.

A esta visão dos agentes como portadores de disposições objetivas, condicionadas por uma estrutura de classes, Ralph Miliband (1973) contrapõe

\footnotetext{
${ }^{6}$ Este papel atribuído ao Estado por Jessop é distinto mas não necessariamente conflituoso com a ressalva apresentada por Simon Clarke (1991) que, reivindicando a crítica de Marx, contesta a existência de um "interesse geral" do capital acima dos interesses particulares como condição para a existência do Estado. Para Clarke, a particularidade do Estado repousa antes na singularidade histórica da resolução de conflitos em cada país. O conceito de "projeto hegemónico" de Jessop integra o Estado dentro dessa condição de historicidade singular, evitando um modelo abstrato e, no limite, funcionalista da análise criticado por Clarke.

7 Cf. Carnoy (1990); Jessop (2002).
} 
a necessidade de um aporte empírico mais apurado na investigação dessas ligações. Esta análise, excessivamente taxada como "instrumentalista", legou-nos pistas importantes no estudo das relações de representação. Segundo Miliband, tratar a "elite do Estado" como uma entidade separada não anula a necessidade de analisar as relações que esta estabelece com a classe economicamente dominante, realçando o caráter histórico de cada processo:

Uma classe que possua ou controle os meios de produção deve também ter uma adequada segurança, pelo menos, com relação à boa vontade e à proteção daqueles que controlam os meios de administração e coerção; e os que controlam o Estado devem ser capazes de confiar na cooperação daqueles que possuem ou controlam os meios de produção. É provável que os principais meios para estabelecer a comunicação e a aprovação decorram do controle dos outros dois meios. (Miliband, 1999: 476)

Para tal, a tese apresentada por Raymond Aron (1964), que dá conta da importância dos detentores de capital na reprodução das relações económicas, mas que minimiza a sua participação em funções de representação política, deve ser questionada. A composição desta "elite do Estado" importa, pois releva, em parte, como é realizada a cooptação e seleção dos representantes em cada país, sublinhando o papel desempenhado pelos governantes na estrutura económica depois da sua passagem pelo exercício do poder. ${ }^{8}$

Atentando a este enquadramento e ao contexto histórico e particular do Portugal moderno, apresentamos justamente uma tese sobre o papel do Estado como base de sustentação da acumulação de capital (Louçã, Lopes e Costa, 2014: 506). Ao tratar os cinco instrumentos de construção do poder económico durante a vigência da ditadura - o disciplinamento da força de trabalho, a concentração forçada de setores produtivos, a proteção contra a concorrência externa, a garantia do mercado colonial e a criação de novas empresas sob o modelo de monopólio - estabelecemos a envergadura da dependência do capital privado face à proteção estatal.

\footnotetext{
${ }^{8} \mathrm{O}$ foco nesta mediação política de interesses particulares de classe, estabelecida pelos agentes do Estado, importa, inclusive, para apurar o conceito de governantes, na medida em que não delimita este universo à mesma categoria do "pessoal do Estado" ou da "burocracia de Estado". Cabe ainda referir que a relação entre a burocracia estatal e os interesses de classe foi tratada tanto por Karl Marx (1984) como por Max Weber. O primeiro, no seu 18 de Brumário de Louis Bonaparte, realça a transformação da burocracia, de instrumento da classe dominante em máquina autónoma consolidada face à sociedade civil, ou seja, a burocracia como a "ilusão do Estado" e garante da sua imagem como interesse do coletivo; como o próprio o afirma na sua Crítica da Filosofia do Direito de Hegel (Marx, 2008: 66) "a burocracia [e os seus agentes] se considera o fim último do estado". Já Weber (2004), que vê na administração burocrática uma das premissas do Estado moderno ocidental, realça a capacidade de influência sobre os organismos de Estado por parte dos funcionários que os integram, relacionando-a com a afirmação da "dominação legal".
} 
Esta base de dominação estendeu-se ao período democrático, mas não sem uma necessária reconfiguração.

A perda dos mercados coloniais e o levantamento da proteção e tutela sobre os mercados internos abriu caminho a três formas de acumulação suplementares de capital. Encontramos, em primeiro lugar, as transferências estabelecidas por via do sistema financeiro, com os bancos a funcionarem como centros de investimentos através de aplicações em monopólios e áreas de rendas garantidas, sendo as privatizações, ocorridas na década de noventa e no início do século, determinantes para este processo. Segue-se um sistema fiscal ancorado nos benefícios e proteção concedidos aos grandes grupos económicos, com o Estado a reequilibrar a dotação orçamental por via do fator trabalho. E, por fim, a manutenção de canais que alimentam o caudal de evasão fiscal, como os offshores e outros instrumentos de fraude, que retiram uma fatia substancial à capacidade tributária do país. Em todos estes processos, o Estado é uma peça central para a reprodução do poder económico, detido por um núcleo da burguesia altamente concentrado e apoiado por uma rede de gestores e administradores que totalizam de 2 a $3 \%$ da população.

Esta leitura, bem a propósito do que nos interessa aqui tratar, situa a reprodução da burguesia em Portugal por via da acumulação de capital, permitindo aferir as relações pelas quais se estabelece uma transposição do poder entre o económico e o político. A replicação do poder da burguesia, defendemos em Os burgueses (2014: 504), está igualmente dependente de um processo de cooptação que se traduz na associação entre os interesses da acumulação de capital e os grupos de governantes e ex-governantes. Esse processo de cooptação promove um robusto processo de mobilidade social ascendente, ao mesmo tempo que gera uma naturalização e interiorização do poder económico como principal fator de estabilidade do poder político.

Importa ainda recordar que a junção de uma teoria crítica do Estado a uma análise empírica capaz de revelar estes laços foi mote de investigações relevantes no contexto internacional, desde logo na importância concedida ao meio escolar e à cultura na reprodução do sistema social (Bourdieu e Boltanski, 1976), bem como nos efeitos destes mecanismos sobre a seleção dos governantes e do pessoal do Estado (Bourdieu, 1989). O nível económico, destacando as relações de propriedade desenvolvidas por ex-governantes e os processos de cooptação por parte de grandes grupos empresariais, adquiriu igualmente relevância (Shleifer e Vishny, 1994; Faccio, 2006). Na análise que se segue impõe-se, portanto, a busca das interligações capazes de elevar, a partir da teoria existente, um conhecimento 
situado, adquirido pela recolha empírica, ao plano de um processo social (Burawoy, 2009: 40). No caso, as relações de classe dos governantes em Portugal nos últimos 40 anos.

\section{Os governantes e a burguesia dirigente e profissional}

Precursor no estudo das classes sociais, Hermínio Martins (2006) concedeu-nos uma análise cuidada da sociedade portuguesa sob a égide dos últimos anos de poder ditatorial (1969-1974). O seu enfoque relacional, que valoriza as aceções de status e poder como campos adstritos à relação de classe, permite, na esteira de Max Weber, aportar numa explicação pluricausal das relações sociais. Referindo-se às disposições e relações de classe, Martins posiciona a "elite política" como um dos centros de poder de uma ditadura que classifica perentoriamente como classista. Análise que se apoia na evidência de uma ordem social marcada por uma mobilidade social condicionada, onde os elementos das "classes baixas" ou socialmente marginais dificilmente ascendem ao restrito círculo da elite política. Como refere Martins:

No caso de Portugal, o acesso à elite política é determinado pela origem social ou pelo recrutamento através de instituições militares ou educativas prestigiantes e altamente selectivas, ou por ambos; através de organizações formais e relações informais, conubiais e conviviais, a elite política torna-se profundamente identificada com a classe alta. (ibidem: 103)

A similaridade de hábitos, padrões de consumo e de afirmação identitária a partir de encontros cerimoniais e cruzamentos familiares, que leva Martins a estabelecer uma íntima conexão entre a elite política e a "classe alta", seria própria de um regime dominado por uma elite diversificada - latifundiários; financeiros; grandes industriais; escalões superiores das Forças Armadas, da função pública e da universidade; episcopado católico e os quadros superiores das profissões liberais -, porém reduzida em número e apoiada num alto grau de concentração económica. ${ }^{10}$ Os processos de cooptação e assimilação de elementos de outras classes, destacados pela via profissional

\footnotetext{
${ }_{9}$ O conceito de elite política usado por Martins colhe em parte na conceção cunhada por Wrigth Mills (1981), que valoriza a relação entre os três pilares da dominação e reprodução da classe dominante, o poder económico, político e militar, realçando os processos de cooptação e absorção das diferentes lideranças.

${ }_{10}$ Para uma análise dos cruzamentos familiares de tipo dinástico entre os representantes do poder económico e do processo de apoio político concedido pelo Estado ao longo do século xx, cf. Costa et al. (2010).
} 
ou política, caracterizam também a reprodução de um poder assente na repressão e no controlo estatal apertado em quase todos os setores da economia (Martins, 2006: 105).

As análises de classe que se seguiram a este período trataram uma realidade já muito modificada, influenciada pela internacionalização da economia, a reconfiguração do setor industrial, o recuo da produção agrícola e o grande alargamento dos serviços. O período democrático, com o crescimento dos serviços públicos sob a égide do Estado, é caracterizado por uma grande transformação na estrutura das classes sociais em Portugal, estudada, desde então, por vários autores (Almeida, Costa e Machado, 1994; Estanque e Mendes, 1997; Queiroz, 2005; Silva, 2009; Carmo, 2013).

Em meio às diversas correntes teóricas que tratam de analisar as classes sociais, a categorização dos indivíduos que ocupam cargos dirigentes no seio do poder executivo levanta algumas questões de ordem conceptual. ${ }^{11}$ Estanque e Mendes (1997), no seu estudo inserido na rede internacional dinamizada por Erik Olin Wright, apresentam uma tipologia de localização das classes que valoriza a distribuição dos "recursos em meios de produção" como divisor social entre aqueles que possuem os meios de produção e os que estão compelidos a vender a sua força de trabalho como único meio para a sua subsistência. Este critério, que colhe na conceção marxista clássica, não figura, porém, como suficiente para uma análise mais acurada da complexa estrutura de classes no capitalismo tardio. Por isso, os autores incorporam no seu quadro de análise a chamada "exploração organizacional ou burocrática" (controlo desigual de recursos organizacionais; autoridade) e a "exploração por credenciais ou qualificações" (controlo desigual de qualificações escassas). Neste quadro, a categoria de "gestor" 12 é separada da de "burguesia/capitalistas", pelo facto de os primeiros apresentarem recursos organizacionais (autoridade sobre subordinados, capacidade de decisão na organização) e posse de qualificações (credenciais e capital escolar), mas ausência de propriedade dos meios de produção. Enquanto a burguesia representava, à data, $0,8 \%$ da população, os gestores qualificados

\footnotetext{
${ }^{11}$ Para uma análise cuidada do debate em torno das tipologias de classe em Portugal, com particular ênfase para o seu enquadramento desde uma perspetiva internacional, cf. Estanque e Mendes (1998).

${ }^{12}$ Como afirmam os autores, "Os gestores são, neste contexto, uma categoria conceptual e sociológica que, na posse dos vários tipos de recursos já referidos, corresponde a uma localização de classe particular: pode tratar-se de um professor, de um médico ou de um presidente de junta de freguesia; pode ser um quadro superior ou médio do aparelho de Estado ou de empresa privada" (Estanque e Mendes, 1997: 67). O caráter abstrato desta categoria insere-se no que Olin Wright (1978) classifica como "lugares contraditórios de classe", no qual os atores assumem comportamentos, juízos e são compelidos por determinações estruturais de diferentes frações de classe.
} 
ascendiam a 2,6\%. Mendes e Estanque realçam ainda o peso do Estado na fatia constituída pelos gestores, uma vez que empregava $14,7 \%$ do total da categoria.

Privilegiando uma abordagem mais centrada nos processos de mobilidade social (trajetórias de classe) e na categorização dos indicadores profissionais, a tipologia cunhada por João Ferreira de Almeida, António Firmino da Costa e Fernando Luís Machado $(1988,1994)$ estabeleceu, numa primeira fase, limites mais alargados para as frações superiores, situando na Burguesia Empresarial e Proprietária (BEP) todos os indivíduos que ocupem a posição de "patrões". Já a categoria de Burguesia Dirigente e Profissional (BDP) fica delimitada às "profissões científicas, técnicas e artísticas", cujos indivíduos desempenhem a profissão na condição de "isolados" (trabalhadores por conta própria), e ao grupo de "diretores e quadros superiores", cujos indivíduos desempenhem a profissão na condição de "isolados" ou "assalariados".

Estes autores consolidaram, mais tarde, esta tipologia com base numa matriz profissional e familiar, na qual o grupo designado por Empresários, Dirigentes e Profissionais Liberais (EDL), e o grupo constituído por Profissionais Técnicos e de Enquadramento (PTE) ocupam as posições cimeiras da estrutura de classes (Machado et al., 2003: 51). No primeiro grupo inserem-se todos os profissionais que desempenhem as suas funções na qualidade de "patrões", mas também os "trabalhadores por conta própria" e por "conta de outrem" que se encontrem na categoria de "Quadros Superiores da Administração Pública, Dirigentes e Quadros Superiores de Empresas", assim como os "Especialistas das Profissões Intelectuais e Científicas" e os "Técnicos e Profissionais de Nível Intermédio" que se encontrem na condição de "trabalhadores por conta própria". Os profissionais destas últimas duas categorias que são trabalhadores por "conta de outrem" totalizam o segundo grupo (PTE). A aplicação desta tipologia realizada por Cristina Roldão (2008), tendo por base os dados do European Social Survey, quantificou a burguesia em $11,6 \%$ da população. ${ }^{13}$

A inclusão da BDP no segundo patamar da estrutura de classes é igualmente secundada por Queiroz (2005), que valoriza o alargamento dos critérios já mencionados da propriedade, da escolarização e da autoridade no contexto de trabalho. Segundo esta autora, a BDP é constituída pelos "gestores de empresas privadas" e os "dirigentes de empresas e serviços estatais". Os valores destas categorias são, todavia, diminutos em Portugal: o contingente total da BDP aumentou de $1,4 \%$ da população ativa em

${ }_{13}$ Para uma análise crítica desta categorização, nomeadamente no que diz respeito à agregação excessiva de frações diferenciadas nas categorias mais altas, cf. Silva (2009: 131). 
1991 para 2,9\% em 2001. O Estado e as grandes e médias empresas concentravam, em 2001, 77,2\% do total da BDP, sendo que nestes dois sectores, $36,4 \%$ dos indivíduos possuíam grau de escolarização superior e universitária.

Destas análises não ressalta, à primeira vista, uma análise especificamente dirigida a uma "elite política", tal como realizada por Hermínio Martins, nem os critérios estabelecidos a partir das características de tipo escolar, organizacional e de relações de propriedade se aplicam corretamente ao contexto temporalmente delimitado do exercício de cargo executivo e eletivo. Os elementos estabelecidos por estes autores para a análise das classes sociais contam, todavia, para uma melhor compreensão da pertença de classe do universo em causa, particularmente da sua relação com a BDP. Para uma leitura mais aprofundada das relações de classe dos governantes cabe, a partir desse enquadramento, assinalar a variação dos indicadores desde a perspetiva longitudinal dos percursos de vida, antes e depois da passagem pelo governo, a saber: o grau de qualificação escolar; as relações de propriedade; o tipo de ligação estabelecido com as empresas. ${ }^{14}$

\section{Os governantes em Portugal: um retrato}

A recolha dos dados referentes aos percursos individuais dos 776 governantes, que ocuparam 1281 cargos de ministro ou secretário de Estado ao longo dos 19 governos constitucionais, resultou em $90 \%$ de informação válida, ou seja, em apenas $10 \%$ dos casos (78 governantes) não se encontraram dados disponíveis. A metodologia e a análise detalhada das relações estabelecidas por este universo foi exposta em capítulo próprio de Os burgueses (2014), ${ }^{15}$ pelo que neste artigo cabe enfatizar, como assinalamos na introdução, alguns dos aspetos particulares das ligações de classe dos governantes.

A primeira dessas relações diz respeito ao capital escolar, um indicador importante por figurar como variável principal da já mencionada exploração credencial. É relevante verificar, à partida, que dos 530 governantes sobre os quais foi possível averiguar a trajetória escolar (68\% do total), apenas 10 obtiveram a formação universitária depois da sua passagem pelo governo. No que concerne às tendências gerais, é possível constatar que 370 governantes $(69 \%)$ se formaram em universidades de Lisboa, seguindo-se as universidades de Coimbra, com 77 governantes (15\%), e do Porto,

\footnotetext{
${ }_{14}$ Aquilo que Estanque e Mendes classificam como "mobilidade estrutural" (1997: 107). Os elementos referentes à mobilidade "intergeracional", valorizados pelas diversas correntes de análise, não estão disponíveis na base de dados.

15 "Até ao infinito e mais além: a política na senda dos negócios" (p. 131-197).
} 
com 57 governantes (11\%). São muito poucos, apenas 22, os governantes que se formaram em outras universidades do país. Também na área de formação dos governantes há uma alta concentração, com destaque para três cursos: licenciatura em Direito (178 governantes, que ocuparam 297 cargos); licenciatura em Economia, Finanças e Gestão (155 governantes, que ocuparam 268 cargos); licenciatura em Engenharia (102 governantes, que ocuparam 181 cargos). Este equilíbrio, como nos revela o Gráfico 1, tem variado significativamente consoante o governo. A partir destes dados é possível aferir que o padrão de recrutamento dos governantes em Portugal é marcado por uma alta incidência de quadros com formação superior, evidenciando uma fraca acumulação de capital escolar associada ao exercício do poder. É ainda significativa a concentração de formação em três universidades nacionais, bem como a hegemonia de três áreas de formação específicas.

GRÁFICO 1 - Formação universitária dos governantes, por governo

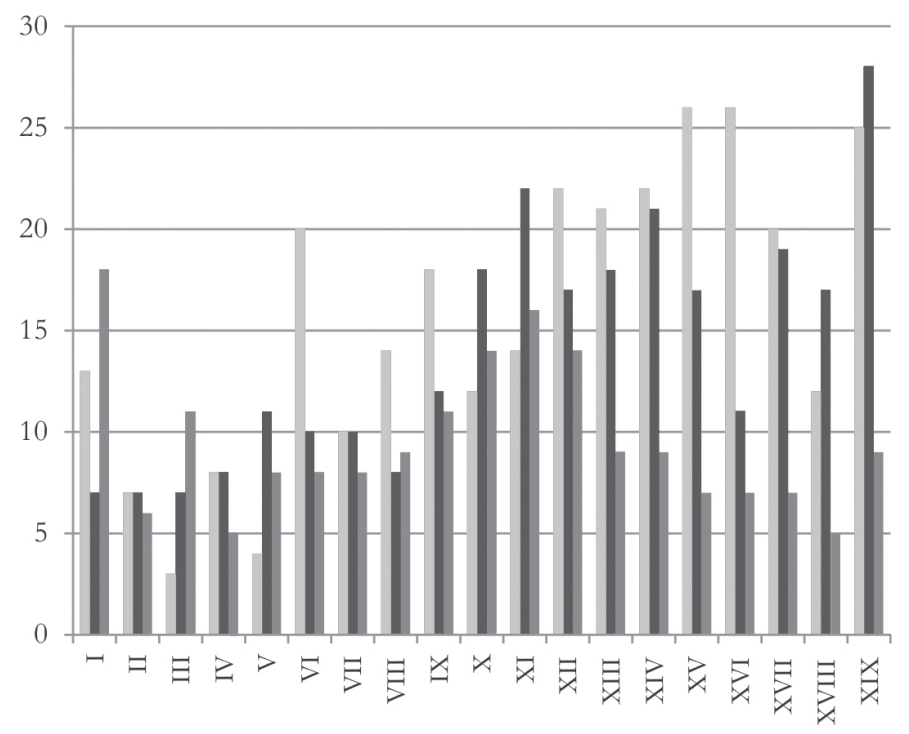

Formados em Direito

- Formados em

Economia/Finanças/Gestão

- Formados em Engenharia 
O segundo domínio que importa analisar é o das relações de propriedade e de autoridade no contexto da organização do trabalho. Do universo de 698 governantes sobre os quais existem informações, verificamos que 415 (59\%) estabeleceram relações empresariais, antes ou depois da passagem pelo governo, seja ao nível da ocupação de posições cimeiras na administração de entidades públicas e privadas, no desempenho de cargos em grandes escritórios de advogados, ou na posse de capital das empresas. A evolução dessas ligações, revelada pelo Gráfico 2, mostra que de todos os governos anteriores a 2005, apenas o IX Governo, formado pelo bloco central, apresenta menos de 50\% de governantes com ligações económicas. Os que revelam essas ligações com mais intensidade são o X Governo (65\% com ligações), o XI Governo (68\% com ligações), o XV Governo (76\% com ligações) e o XVI ( $80 \%$ com ligações); em contrapartida, o VIII Governo (51\% com ligações), o IX Governo (48\% com ligações), o XII (36\% com ligações) e o XIII ( $25 \%$ com ligações) são os que menos ligações apresentam. ${ }^{16}$

\section{GRÁFICO 2 - Ligações económicas estabelecidas pelos governantes, por governo}

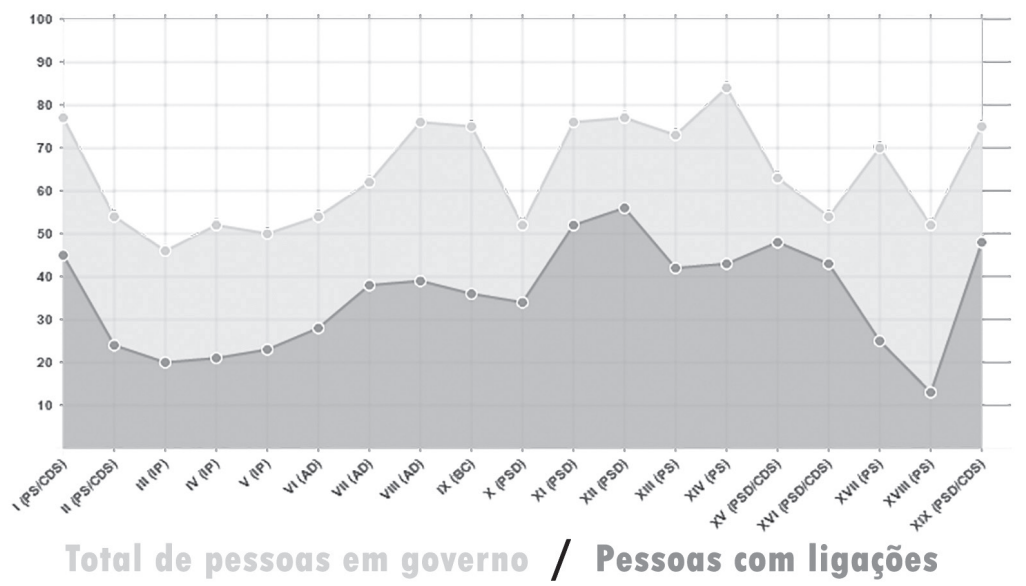

Fonte: Base de dados Os burgueses (2014), disponível em http://www.osburgueses.net/

De forma a refinar esta análise, ligando-a ao foco da exploração capitalista (posse dos meios de produção) e da exploração organizacional (hierarquia organizacional), cabe destrinçar o tipo de relação estabelecida. Essa opção

\footnotetext{
${ }_{16}$ Para obter o número de ligações por partido, cf. Louçã, Lopes e Costa (2014: 151).
} 
permite verificar que dos 415 governantes que constituíram relações económicas, apenas 6 o fizeram exclusivamente por via da propriedade direta da posse de capital. Já os que somaram a posse de capital à ocupação de cargo hierárquico relevante antes da passagem pelo governo totalizam os 26 governantes. No caso de 20 governantes que já haviam ocupado cargos em empresas, as relações de propriedade foram estabelecidas apenas depois da passagem pelo governo. Já o contrário, um percurso iniciado pela relação de propriedade para depois do governo alcançar os lugares cimeiros em empresas, foi realizado por apenas 2 governantes. Por fim, para 25 destes governantes a passagem pelo governo significou o acesso à propriedade de capital e a uma ou mais posições privilegiadas a nível organizacional.

TABELA 1 - Governantes por ocupação e associação de relação económica, antes ou depois de governo

\begin{tabular}{lccc}
\hline Autoridade & Propriedade & $\mathbf{N}{ }^{\circ}$ governantes & $\begin{array}{c}\text { \% do total com } \\
\text { ligações }\end{array}$ \\
\hline antes & & 171 & $41 \%$ \\
\hline depois & 165 & $40 \%$ \\
\hline & antes & 3 & $1 \%$ \\
\hline antes & depois & 3 & $1 \%$ \\
\hline depois & antes & 26 & $6 \%$ \\
\hline antes & antes & 25 & $6 \%$ \\
\hline antes & antes & 20 & $5 \%$ \\
\hline
\end{tabular}

Fonte: Base de dados Os burgueses (2014), disponivel em http://www.osburgueses.net/

Foi, no entanto, pela via exclusiva da ocupação de cargos de direção que a maioria dos governantes constituiu a sua ligação. Foram 171 os governantes que já exerciam funções de direção aquando da sua passagem para o governo, e 158 os que alcançaram essas posições depois de desempenhado o cargo governativo. Esta análise revela que ao contrário do que acontece a nível escolar, a passagem pelo governo está associada a uma forte mobilidade social ascendente, com $28 \%$ dos governantes sobre os quais existe informação disponível a estabelecer uma relação económica dominante apenas depois da passagem pelo governo ( $47 \%$ do total com ligações). Já o facto de $31 \%$ dos governantes (53\% do total com ligações) aportar no 
governo vindo de um cargo de direção empresarial é também revelador do padrão de recrutamento levado a cabo pelos partidos na escolha dos seus representantes.

Estas tendências não revelam, contudo, a evolução das ligações estabelecidas em termos da dimensão das empresas (número de trabalhadores) ou da intensidade dos cargos desempenhados (número de ligações). Essas duas dimensões importam na medida em que apreendem o tipo de trânsito estabelecido pelos governantes e as estratégias de cooptação do poder económico, assim como valorizam os critérios estabelecidos na literatura das classes sociais, desde logo no que diz respeito à exploração organizacional a partir de uma perspetiva longitudinal. Para tal, e à falta de informação continuada sobre o número de trabalhadores empregados pelas empresas assinaladas, cabe usar a categoria de "grandes grupos económicos", ${ }^{17}$ construída em Os burgueses (2014: 158), pelo facto de englobar, inequivocamente, empresas de grande dimensão (mais de 100 trabalhadores).

A relevância desta abordagem confirma-se pela constatação de que quase metade dos governantes com ligações a empresas se associaram, antes ou depois do governo, a estes grandes grupos. Foram 170, mais de um quinto do total, os governantes que se vincularam a estes grupos, ocupando 311 cargos governativos (um quarto das posições de poder), o que revela uma maior repetição em funções executivas quando comparado com os restantes. A composição dos X, XI e XII Governos, que apresentam 63\%, $42 \%$ e $44 \%$ de representantes ligados aos grandes grupos (Gráfico 3), determina em grande medida esta tendência.

Este trânsito privilegiado verificado nas altas instâncias do poder económico em Portugal revela ainda um padrão diferenciador na cooptação dos governantes por parte destas grandes empresas. Do total de governantes desta categoria, apenas 56 (33\%) estabeleceram o seu vínculo com uma ou mais destas empresas antes de aportarem no governo, sendo que 114 (67\%) apenas acederam a este círculo restrito depois de deixarem as funções executivas. Verificamos, igualmente, que este conjunto de governantes beneficiou comparativamente mais com a sua passagem pelo governo, posto que se regista um avolumar considerável de cargos ocupados a nível empresarial: antes da chegada ao governo, estes governantes desempenharam 320 cargos em empresas, sendo que em 57 casos não tinham desempenhado nenhum cargo, já no período pós-governo contabilizamos a ocupação de 1350 cargos em empresas.

${ }_{17}$ Grupo Mello, Champalimaud, BES, BCP, Santander, Mota-Engil, PT, BPI, CGD, SONAE, Jerónimo Martins e Amorim. 
O estreitamento do exame aos governantes na categoria referente aos grandes grupos permite-nos identificar, num patamar económico superior, uma tendência preponderante de cooptação de ex-governantes, em contraponto com a colocação de quadros empresariais sem experiência política em cargos governativos, o que acontece com menor intensidade. $\mathrm{O}$ facto de nesta categoria o processo de acumulação e ascensão social ser consideravelmente mais acelerado, marcado inclusive pela maior ocupação de cargos executivos, aponta para um fenómeno de interligação do poder político e económico, plasmado na multiplicação de redes e cargos desempenhados por estes ex-governantes.

\section{GRÁFICO 3 - Número de governantes associados ou que vieram a associar-se aos grandes grupos económicos, por governo}

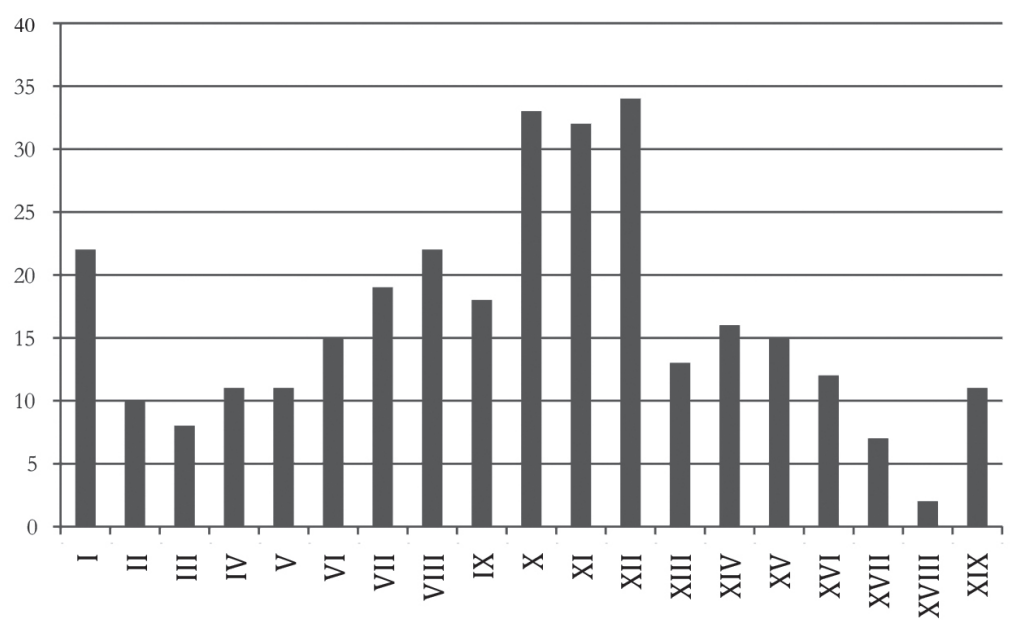

Fonte: Base de dados Os burgueses (2014: 159).

\section{Conclusão}

A relação de cooptação, que se traduz na associação entre os detentores de capital e os grupos de governantes e ex-governantes, revela-se como um processo social de grande relevância. O estudo do trânsito estabelecido pelos governantes, antes e depois da sua passagem pelo poder executivo, aponta para o estabelecimento de vínculos com o poder económico de forma constante e transversal aos diversos governos ao longo do período observado. Apenas nos governos mais recentes, cujos membros cessaram funções há relativamente pouco tempo, a percentagem de ligações não supera os $50 \%$ dos governantes. Essas ligações intensificam-se, inclusive, 
nos governos que dinamizaram uma das formas assinaladas de acumulação suplementar de capital, as transferências estabelecidas por via do sistema financeiro, apoiadas nos processos de privatização, no caso o período que vai do X ao XVI Governos.

Ao observarmos a trajetória individual dos governantes, destrinçando os níveis da mobilidade estrutural (propriedade; autoridade; qualificações), verificamos, em primeiro lugar, que a cooptação de dirigentes para os cargos governativos obedece a um elevado padrão de qualificações escolares. Mais de dois terços dos governantes em Portugal possuía formação superior antes de chegar ao governo, sendo provenientes, na sua maioria, das universidades do Porto, Coimbra e Lisboa. O percurso escolar destes governantes revela ainda uma uniformização balizada por três cursos, Direito, Economia e Engenharia, pelo que podemos falar de uma estratégia assente na acumulação de capital escolar específica assumida pelos partidos nas escolhas dos seus principais quadros. Essa evidência reforça-se pela quase inexistência de formação escolar associada ao desempenho do cargo ou ao período que se lhe segue: a entrada nos cargos executivos está determinada por um grau de qualificação superior ao existente em todas as frações da burguesia, inclusive a BDP, havendo um espaço muito reduzido para a ascensão de quadros sem qualificações.

As relações de autoridade e propriedade revelam tendências distintas. Há um conjunto significativo de governantes que provêm de cargos profissionais desprovidos de uma posição de autoridade ou propriedade dominante. Neste conjunto, porém, o exercício integral de cargos legislativos (deputados) e do ensino superior (professores) constituem a maioria dos casos, pelo que não sendo aqui contabilizados como ligações económicas, acarretam necessariamente algum grau de autoridade sobre outros. Os governantes nesta condição são, ainda assim, uma minoria. Na maioria dos casos, duas tendências marcam as relações económicas estabelecidas antes ou depois da passagem pelo cargo governativo. A primeira dá conta do pouco peso das relações de propriedade nas trajetórias dos governantes, com apenas $2 \%$ a estabelecer ligações económicas exclusivamente por essa via. Essa constatação remete, por exclusão, para os $81 \%$ dos governantes que constituíram ligações pela via exclusiva de cargos de autoridade, aos quais se somam 17\% que o fizeram também, em paralelo, por via da propriedade.

Ao tratar estes números, o que remete a maioria deste universo para a categoria dos "gestores" e da BDP, desde uma perspetiva longitudinal, alcançamos uma melhor interpretação do trânsito estabelecido por estes dirigentes. $O$ facto de quase um terço do total de governantes alcançar posições economicamente dominantes apenas depois de passarem pelo governo, 
revela um processo significativo de mobilidade social ascendente associado ao exercício das funções. Por outro lado, o facto de $31 \%$ de governantes que integram o governo provirem de uma posição dominante manifesta uma estratégia levada a cabo pelos partidos, que se socorrem de quadros firmados a partir da atividade empresarial. Assumimos, igualmente, a limitação desta análise no que diz respeito à mobilidade "intergeracional”, cuja recolha de dados se afigura difícil, mas que tornaria a análise mais refinada no que concerne à mobilidade ou reprodução social dos lugares de classe.

Esta análise é, não obstante, insuficiente para situar os diversos níveis de poder económico, uma vez que engloba todas as ligações de todos os governantes. De forma a particularizar as relações situadas nas frações superiores do poder económico, recorremos à categoria de "grandes grupos económicos". O tratamento deste conjunto revelou diferenças significativas. Este grupo diminuto de entidades cativou, nos últimos quarenta anos, não só quase metade dos governantes com ligações, como seguiu uma estratégia de cooptação muito mais agressiva do que as restantes empresas. $\mathrm{O}$ facto de mais de dois terços dos governantes chegarem a estes grupos económicos apenas depois de passarem pelo governo, demonstra a valorização e preocupação dos últimos em respaldar o seu poder económico por via do capital político destes dirigentes. Essa transposição de papéis resulta ainda, atentando na trajetória desta categoria de governantes, na sua transformação em quadros estruturantes da economia, uma vez que o número de cargos desempenhados em empresas, depois da passagem pelo executivo, mais do que quadruplica. Muitos regressam mesmo ao governo, ocupando, no total, um quarto dos cargos governativos, pese embora representarem apenas um quinto dos governantes.

Ao aduzirmos o papel desempenhado pelos governantes no entrelaçamento e na sustentação do poder económico, reforçamos a tese que situa o Estado como elemento central para a reprodução da burguesia. A replicação desta dominação de classe em Portugal depende do processo de cooptação, que figura como uma das características complementares de uma estratégia de acumulação historicamente estabelecida. Esta interdependência é própria de um regime marcado pelo atraso económico e pela extração rentista como instrumento primordial de exploração. Esta conclusão contraria a proposição apresentada pelas correntes (neo)liberais, segundo a qual o Estado assume uma autonomia total face aos conflitos endógenos da sociedade. Mas mais do que estabelecer uma classificação abstrata da autonomia do Estado, esta análise busca apontar as vias pelas quais os centros de decisão política são alvo de captura pelos detentores de capital, revelando a função de manutenção e reprodução destas relações como um dos princípios do poder de Estado no contexto do Portugal contemporâneo. 


\section{Referências bibliográficas}

Aron, Raymond (1964), La lutte des classes. Paris: Galimard.

Almeida, João Ferreira de; Costa, António Firmino da; Machado, Fernando Luís (1988), Familia, estudantes e universidade. Lisboa: CIES-ISCTE / CELTA.

Almeida, João Ferreira de; Costa, António Firmino da; Machado, Fernando Luís (1994), "Recomposição social e novos protagonismos", in António Reis (org.), Portugal: 20 anos de democracia. Lisboa: Círculo de Leitores, 307-330.

Bourdieu, Pierre (1989), La noblesse d'État: Grandes écoles et esprit de corps. Paris: Minuit.

Bourdieu, Pierre; Boltanski, Luc (1976), "La production de l'idéologie dominante", Actes de la Recherche en Sciences Sociales, 2(2-3), 3-73.

Burawoy, Michael (2009), The Extended Case Method: Four Countries, Four Decades, Four Great Transformation and One Theoretical Tradition. Berkeley: University of California Press.

Carmo, Renato Miguel (2013), Portugal: uma sociedade de classes. Lisboa: Le Monde Diplomatique.

Carnoy, Martin (1990), Estado e teoria política. São Paulo: Papirus.

Clarke, Simon (1991), The State Debate. London: Macmillan.

Costa, Jorge; Fazenda, Luís; Honório, Cecília; Louçã, Francisco; Rosas, Fernando (2010), Os donos de Portugal. Porto: Afrontamento.

Durkheim, Émile (1973), A divisão social do trabalho. São Paulo: Abril [ed. orig.: 1893].

Estanque, Elísio; Mendes, José Manuel (1997), Classes e desigualdades sociais em Portugal: um estudo comparativo. Porto: Afrontamento.

Estanque, Elísio; Mendes, José Manuel (1998), "Análise de classes e mobilidade social em Portugal”, Revista Crítica de Ciências Sociais, 52/53, 173-198.

Faccio, Mara (2006), "Politically Connected Firms", American Economic Review, 96, 369-386.

Friedman, Milton (1962), Capitalism and Freedom. Chicago: University of Chicago Press. Jessop, Bob (1990), State Theory: Putting Capitalist States in their Place. Oxford: Polity Press.

Jessop, Bob (2002), The Future of the Capitalist State. Cambridge: Polity.

Louçã, Francisco; Lopes, João Teixeira; Costa, Jorge (2014), Os burgueses. Lisboa: Bertrand.

Machado, Fernando Luís; Costa, António Firmino da; Mauritti, Rosario; Martins, Susana da Cruz; Casanova, José Luís; Almeida, João Ferreira de (2003), "Classes sociais e estudantes universitários: Origem, oportunidades e orientações", Revista Crítica de Ciências Sociais, 66, 45-80.

Martins, Hermínio (2006), Classe, status e poder. Lisboa: ICS.

Marx, Karl (2008), Crítica da filosofia do direito de Hegel. São Paulo: Boitempo [ed. orig.: 1843]. 
Marx, Karl (1984), O 18 de Brumário de Luís Bonaparte. Lisboa: Edições Avante [ed. orig.: 1951].

Miliband, Ralph (1973), The State in Capitalist Society. London: Quartet Books.

Miliband, Ralph (1999), “Análise de classes”, in Anthony Giddens; Jonathan Turner (orgs.), Teoria social hoje. São Paulo: Unesp, 470-502 [ed. orig.: 1987].

Mills, Wright (1981), A elite do poder. Rio de Janeiro: Zahar Editores.

Parsons, Talcott (1988), El sistema social. Madrid: Alianza Editorial.

Poulantzas, Nicos (1978), O Estado, o poder, o socialismo. Lisboa: Moraes.

Queiroz, Cidália (2005), Classes, identidades e transformações sociais. Porto: Campo das Letras.

Roldão, Cristina (2008), Testando modelos de operacionalização. Uma análise exploratória de modelos de operacionalização da estrutura de classes no quadro do European Social Survey - Round. Lisboa: CIES.

Shleifer, Andrei; Vishny, Ward (1994), "Politicians and Firms", The Quarterly Journal of Economics, 4, 996-1025.

Silva, Manuel Carlos (2009), Classes sociais: condição objectiva, identidade e acção colectiva. Ribeirão: Húmus.

Therborn, Göran (1978), What Does the Ruling Class When it Rules? London: NLB.

Weber, Max (2004), Economia e sociedade: Fundamentos da sociologia compreensiva, vol. 2. São Paulo: UNB [ed. orig.: 1920].

Wright, Erik Olin (1978), Class, Crisis and the State. London: Verso.

Artigo recebido a 11.07.2015

Aprovado para publicação a 10.11.2015

\section{Adriano Campos}

Doutorando em Sociologia das Relações de Trabalho, Desigualdades Sociais e Sindicalismo na Faculdade de Economia da Universidade de Coimbra/Centro de Estudos Sociais Avenida Dr. Dias da Silva 165, 3004-512 Coimbra, Portugal

Contacto: adrianopcampos@gmail.com

\section{Jorge Costa}

Deputado da Assembleia da República. Investigador independente

Contacto: jorgecosta1975@gmail.com

\section{João Teixeira Lopes}

Departamento de Sociologia da Faculdade de Letras da Universidade do Porto

Via Panorâmica, s/n, 4150-564 Porto, Portugal

Contacto: jmteixeiralopes@gmail.com 


\section{Francisco Louçã}

Departamento de Economia do Instituto Superior de Economia e Gestão da Universidade de Lisboa Rua do Quelhas 6, 1200-781 Lisboa, Portugal

Contacto: francisco.lou66@gmail.com

\section{Nuno Moniz}

Doutorando em Ciências da Computação, Faculdade de Ciências da Universidade do Porto

Rua do Campo Alegre 1021/1055, 4169-007 Porto, Portugal

Contacto: nunompmoniz@gmail.com

\section{Representatives and Dominants: Rulers and Class Relations in Portugal}

This article discusses the relationships established between capital owners and the groups of rulers and former rulers, embracing a critical perspective capable of enhancing the State's role in the definition of economic power. Special attention is given to the cooptation process, an analysis that includes data on 776 rulers who occupied 1281 positions in the 19 constitutional governments (1976-2014).

Keywords: bourgeoisie; economic power; social cooptation; State; social classes.

\section{Représentants et dominants: Les gouvernants et les rapports de classe au Portugal}

Cet article se penche sur les liens établis entre les détenteurs de capital et les groupes de gouvernants et d'ex-gouvernants, en partant d'une perspective critique à même de mettre en relief le rôle de l'État dans la structuration du pouvoir économique. Un regard attentif y est porté sur le processus de cooptation dans une analyse qui englobe des données ayant trait aux 776 gouvernants qui occupèrent 1281 postes au sein des 19 gouvernements constitutionnels (1976-2014).

Mots-clés: bourgeoisie; classes sociales; cooptation social; État; pouvoir économique. 